Las comunidades

indígenas de

Jinotega, resistencia

y pertenencia.

Lic. Ruth González García 


\section{Las comunidades indígenas de Jinotega, resistencia y pertenencia ${ }^{1}$.}

Copyright $\odot 2018$ UNAN-Manag Todos los DerechosReservados.

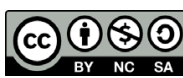

Lic. Ruth González García

Docente-Investigadora

Departamento de Historia,

Facultad de Humanidades y

Ciencias Jurídicas

https://orcid.org/0000-0001-

5408-1385

ruthgonzalez0290@gmail.com

Recibido: $20 / 08 / 2018$ Aceptado: 25/10/2018

\section{The indigenous communities of Jinotega:} resistance and belonging

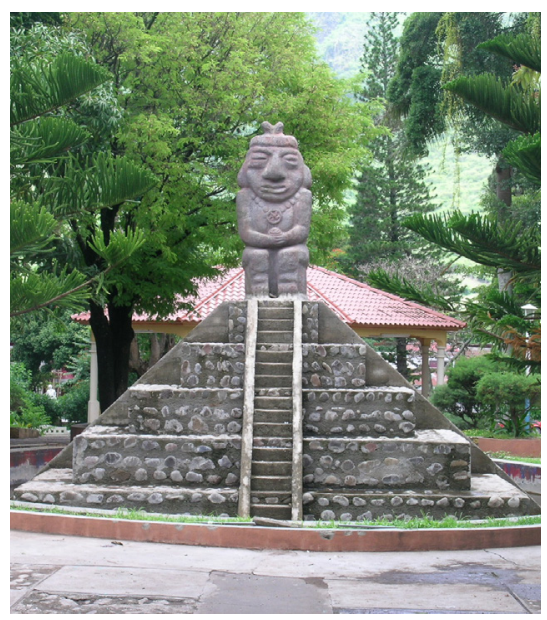

Parque de Jinotega / Foto: Dieter Jungblut

\section{PALABRAS CLAVE}

Historia oral, identidad cultural, pervivencia, territorio, indígena, comunidad indígena.
El objeto de estudio es entender los elementos propios de la Comunidad Indígena de Jinotega, un grupo social que se auto identifican como herederos de la cultura indígena chorotega y que en la actualidad se encuentran asentados en el departamento de Jinotega. El estudio de los grupos étnicos representa un valioso cúmulo de conocimientos y saberes tradicionales que se han conservado en la memoria de la población por medio de la transmisión oral, es decir, a partir del mito se ha logrado mantener viva la historia de sus antepasados. En este sentido, el presente artículo está dirigida a exponer los resultados que se han generado de ese contacto directo con la población, donde la Historia Oral como método, técnica y fuente representa la herramienta más importante para rescatar ese pasado que permanece activo entre los pobladores.

\section{ABSTRACT}

The object of study is to understand the elements of the Indigenous Community, a social group that self-identifies as heirs of the Chorotega indigenous culture and who are currently settled in the department of Jinotega. The study of ethnic groups represents a valuable accumulation of knowledge and traditional knowledge that have been preserved in the memory of the population through oral transmission, that is, from the myth it has been possible to keep the history of their ancestors alive. In this sense, this article is aimed at exposing the results that have been generated from that direct contact with the population, where Oral History as a method, technique and source represents the most important tool to rescue that past that remains active among the inhabitants.

\section{KEYWORDS}

Oral history, cultural identity, pervivence, territory, indigenous, indigenous, community.

\footnotetext{
1. Articulo realizado a partir de un proceso de investigación financiada por los Fondos para Proyectos de Investigación (FPI).

2. Licenciada en Historia. Actualmente docente investigadora del departamento de Historia de la Facultad de Humanidades y Ciencias Jurídicas de la UNAN-Managua, y egresada de la Maestría en Estudios Históricos Latinoamericanos y del Caribe. Diplomado en Gestión de Archivos, y postgrado en Teoría y Metodología de Historia Regional y Local, así como cursos libres. Colaboradora en diferentes proyectos de investigación, entre ellos Historia de la Lotería, Historia del municipio de El Castillo. Ponente y asistente en seminarios, congresos, conferencias nacionales e internacionales.
} 


\section{Introducción}

Este artículo es parte del resultado de un proceso de investigación como requisito de culminación de la tesis de Maestría en Estudios Históricos Latinoamericanos y del Caribe que lleva por título Rescatando el legado histórico de las comunidades indígenas de Jinotega. Una aproximación histórico-social en el siglo XX. Investigación desarrollada bajo programa de maestría en estudios históricos, que actualmente está finalizando el departamento de Historia de la UNAN-Managua.

Centra su interés en el estudio de una población étnica que se localiza en el norte de Nicaragua y que es actualmente reconocida ${ }^{3}$ como descendientes de uno de los grupos que estaban asentados en el territorio a la llegada de los europeos, es decir, nativos de la zona a los que regularmente se les ha llamado indígena o indio, este último término aplicado casi siempre con tono despectivo y abusivo.

Para fines de la investigación, se ha definido al indígena ${ }^{4}$ como todo aquel individuo que pertenezca a una comunidad étnica, es decir, a una comunidad estructurada por relaciones de parentesco de tipo clánico-linájico (Membreño; 1998). Interesa este concepto porque centra la identificación del individuo a partir de su integración social, ya sea en castas o comunidades.

Bajo esta lógica, el trabajo investigativo se planteó la siguiente interrogante ¿Cómo se expresa la pervivencia cultural de los grupos originarios en las Comunidades Indígenas de Jinotega? y, en consecuencia, se propone identificar y explicar los elementos culturales que aún se expresan como parte de ese vínculo histórico que mantiene la población de las Comunidades indígenas de Jinotega con sus antepasados y que definen actualmente su identidad colectiva, entendiéndose esto como ese elemento abrazador que los identifica con un pasado cultural común y que a su vez, lo diferencia de otros grupos poblacionales.

En cuanto a la ruta metodológica, el artículo fue desarrollado a partir de la aplicación de métodos y técnicas propias del quehacer de la ciencia histórica como son el análisis y síntesis, análisis de fotografías y testimonios, este último aprovechado a la luz del cuerpo teórico que ofrece la Historia Oral. En consecuencia, aquí se presentan algunas fuentes primarias que fueron construidas en el transcurso de la investigación, dada la escasez de argumentos que había en algunos aspectos de importancia que se querían retomar como ejes de análisis.

\section{Contexto geográfico e histórico de las comunidades indígenas de Jinotega}

La comunidad indígena de Jinotega es un grupo poblacional que en la actualidad se identifican como Chorotega, es decir, descendientes del primer grupo mesoamericano que emigró hacia el actual territorio de Nicaragua entre los siglos VIII y XV, a consecuencia de la caída de las ciudades de Teotihuacan y Tula de la región de Anahuac en México.

Existe una serie de contradicciones en cuanto a la identificación exacta del grupo étnico que se asentó en el centro de Nicaragua, dado sobre todo por las escasas investigaciones que se han

3. Amparados ante las leyes de la República y que gozan actualmente del reconocimiento de organismos, asociaciones, coordinaciones y otras alianzas que se ocupan de velar por la integración y participación de estos en el sector político, social y económica de los Estados donde se encuentran radicando.

La Constitución Política de Nicaragua Arto No.5 confirma el pluralismo étnico como principio fundamental del Estado de Nicaragua, sentándose las bases para el respeto a la identidad e historia de los pueblos originarios, decisión que se tradujo en la libertad de administrar sus asuntos locales, mantener sus propias formas de organización social e institución de su liderazgo tradicional como son los Consejos de Anciano.

A nivel nacional forman parte del Movimiento Indígena de Nicaragua (MIN) y la Coordinación de Pueblos indígenas del Pacifico, Centro y Norte de Nicaragua

4. Hay dos corrientes que se encargan de definirlo en base a criterios particulares. La primera corresponde a los esencialistas, es decir, aquellos estudiosos que plantean que se pertenece a cierta condición étnica porque se nace en ella, es algo dado, no cultural, heredado de sus padres y a su vez de sus abuelos. No hay otra vía más que por herencia materna. 


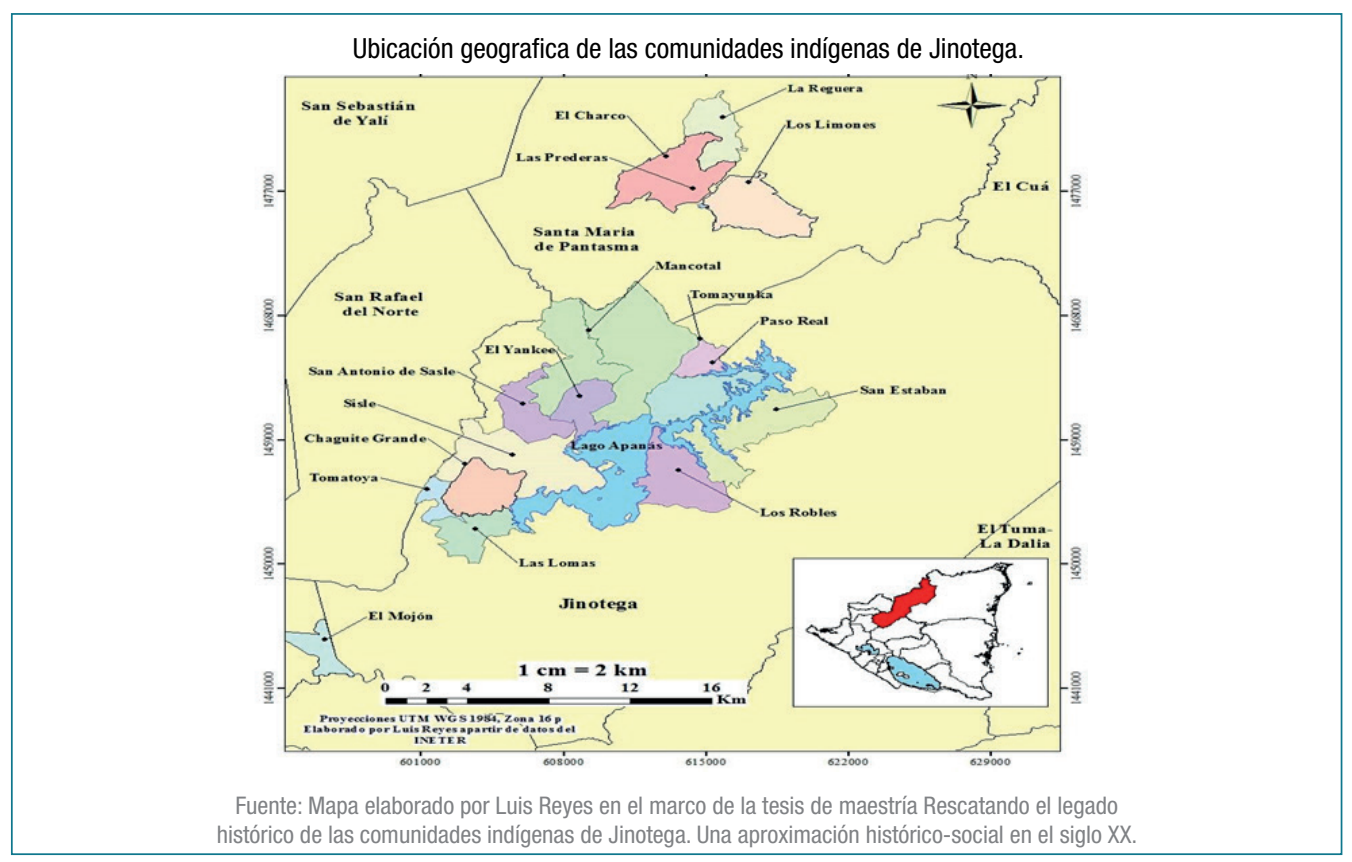

realizado en el lugar. El debate se encuentra entre los Matagalpas, y Chorotegas, sin embargo, una realidad papable es que las comunidades Indígenas de Jinotega han adoptado la identidad chorotega como parte de su reconocimiento cultural y legado precolombino, así lo demuestran sus prácticas religiosas, cosmovisión, mística y forma de vida.

El territorio de las comunidades indígenas de Jinotega, abarca un total de 43.889 manzanas de extensión divididas en dos lotes: 36, 000 en el lote número 1 y 7,000 en el lote número 2. La población agrupa alrededor de 40, 000 personas que habitan principalmente en dos municipios, el de Jinotega donde existen aproximadamente 35, 000 indígenas, y el de Santa María de Pantasma, en el mismo departamento donde hay una cifra estimada de 4000 a 5000 indígenas (Romero; 2008).

En el mapa se puede apreciar la distribución espacial de las comunidades en estudio, la mayoría asentadas a orillas del lago Apanás (Lote No. 1), el que fue construido en 1964 en territorio de indígena sin consultársele y mucho menos tomándole consideración en los beneficios económicos que este generó.

\section{La tierra, símbolo de identidad}

Para Francisco Pérez Estrada (1956), la comunidad indígena es una forma de propiedad comunal, establecida por la corona española para los indios de América (p. 82), esta concepción se fundamenta en el dominio, reducción y repartimiento de las propiedades indígenas por parte de la corona española durante el proceso de colonización en el siglo XVI.

Desde entonces, se manejaba que la tierra era por excelencia la fuente de riqueza (de manera comunitaria), es decir que, a partir de ella, se cosechaban los alimentos básicos que garantizaban su subsistencia, y más aún, pesaba la visión de espiritualidad que alimentaba su sentido de pertenencia, la que se evidenciaba a partir de ceremonias, cultos, danzas y otras expresiones de solemnidad. 
Esta idea ha sido trasmitida a partir del mito y la oralidad. Por ello, no es extraño que la mayoría de los pobladores que se auto reconocen como descendientes de grupos étnicos pasados, lo hacen a la luz del elemento tierra, es decir, son indígenas porque en ese espacio se asentaron grupos indígenas $y$, por lo tanto, la tierra es fuente de nexo de una generación con otra. Sin embargo, este elemento es de todos y de nadie a la vez.

Para las comunidades indígenas la tierra representa ese elemento de identidad que los cohesiona como casta, más allá de las necesidades materiales que pueden satisfacerse de ella, los miembros se reconocen entre sí, como hijos de los ancestros que poblaron el espacio que hoy les pertenece, generándose lazos de amistad y compañerismo: en Jinotega su identidad es por la tierra, el sentido de pertenencia y posesión de la tierra es vista no solo como un medio de trabajo si no como la madre tierra. (González; 2015)

Muestra de esa unión fuerte del terruño se visualiza en el reconocimiento de las familias indígenas por sus apellidos, sobresaliendo entre los jinoteganos los González, Herrera, Hernández, Díaz, Meléndez, Castro, Centeno, entre otros. Aunque las comunidades se encuentran dispersas y los medios de transportes no son fluidos, aún se mantiene un vínculo vecinal fuerte que se visualiza en el reconocimiento de miembros y familias indígenas, al menos entre la población de mayor edad. Por ello, cuando se entra en contacto con una persona desconocida, es común que los pobladores pregunten de qué comunidad y familia provienen, para tener una idea del origen de ese miembro. Si se logra el reconocimiento pleno del individuo automáticamente se genera la confianza y solidaridad, pues se considera una relación casi de parentesco.

\section{Saberes tradicionales}

Un elemento característico de este grupo étnico es el fuerte apego y condicionamiento que tienen las fases lunares en la vida cotidiana, esto se expresa en muchos sentidos, pero principalmente en aquellas actividades que están orientadas a la productividad de la localidad, como la agricultura:

En la siembra se busca la luna para sembrar, para cosechar... esto nos ha provocado contrariedad con los ingenieros que estudian sistemas de cultivos... Si nosotros vamos a sembrar árboles frutales lo hacemos en luna escondida (un dia antes de la luna nueva), son dos o tres años y ya tienen cosecha, en la luna tierna no sirve

(González, L; 2016).

Además de la agricultura, se puede observar que en actividades tan sencillas como la siembra de árboles, esterilización de animales, y recogida de las cosechas se efectúan de acuerdo al calendario lunar, la mayoría durante la fase de luna nueva (también llamada novilunio o interlunio): Si uno siembra en la luna tierna la semilla no germina bien, se produce menos y bastante mal, cuando se va a recolectar el frijol debe estar en luna sazona para que no le entre el gorgojo porque lo pica todo, así igual se sucede con el maíz, con el arroz y con el trigo (Altamirano; 2016)

Entre la población también se ha manejado que los ciclos de la luna pueden influenciar en la definición del sexo de los hijos: Mi abuelita decía que la niña se forma cuando la luna está tierna y que el varón -lo hace- cuando la luna está decreciente (cuarto menguante), entonces cuando la mujer quería parir un hijo se alimentaba bien y no tenía relaciones muy seguidas, esperaba la luna... (González, L; 2016) De acuerdo a los deseos de las parejas, si querían un o una hija, cumplían con estas condiciones. 
Esta práctica es un elemento arraigado y sobresaliente que ha sido heredado de una generación a otra, siempre manteniéndose constante la idea de influencia controladora del ciclo lunar.

\section{Producción cerámica}

Otra manifestación de los saberes tradicionales se ha evidenciado en la elaboración de cerámicas de barro, técnica que ha prevalecido a consecuencia de su transmisión oral de una generación a otra. En la actualidad encontramos viva esta práctica propia de los pueblos originarios en la comunidad Las Cureñas, donde se registra su continuidad, uso y aprovechamiento.

En las comunidades, anteriormente era común el uso del barro en la elaboración de utensilios domésticos como ollas, comales, y recipientes destinados para el almacenamiento de bebidas (agua y refrescos), conocidos popularmente como tinajas:

Me enseñaron mis abuelos, de generación en generación, antes era utilitarios, para usar dentro de la casa elaborados a mano y molde, se hacian jarros, comales, ollas grandes para cocer nacatamales, las pasadoras (tinajas grandes) para hacer chichas, para hacer agualoja, sartenes para cuajar la leche. A los niños les hacian comalitos y ollitas para que jugaran

(Herrera; 2016)

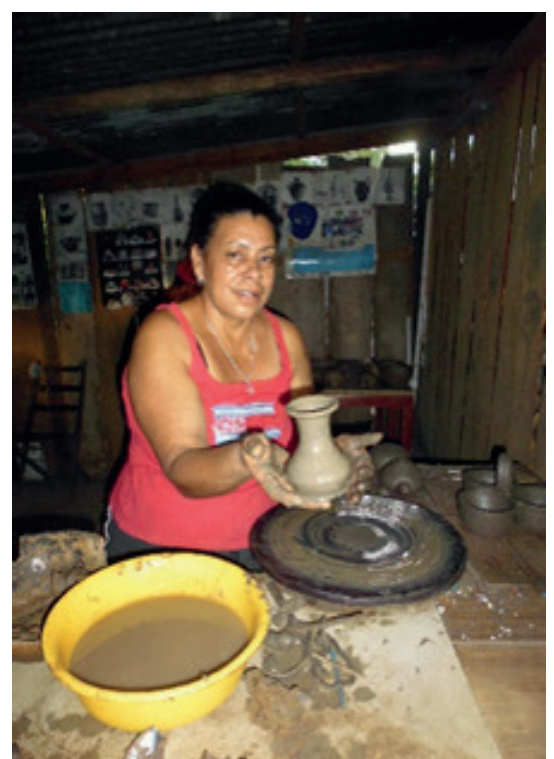

Luz Marina Herrera, artesana de Las Cureñas, Jinotega. Fuente: Fotografía tomada a partir del trabajo de campo realizado en octubre de 2015

Todavía para la década de 1950 era común la elaboración de estos productos, así lo cuenta Migdalia López al referirse a una actividad cotidiana que se gestaba en el seno de su familia: Jalaba agua en burro, en calabazo, en tinajas de barro, porque mi mamá hacía comales, jarros, sartenes, ollas (Romero; 2009: 28). Las personas se dedicaban a elaborar estos bienes generalmente para el autoconsumo y compartir entre parientes y amigos cercanos como muestra de estima y relaciones de buena vecindad.

El uso del barro fue trasmitiéndose a las siguientes generaciones a través del juego y la réplica, era común que los niños utilizaran para su recreación pequeños utensilios (de cocina) en miniatura que hacían más atractivos y creativos sus juegos infantiles. Sin darse cuenta, que en el proceso se estaban apropiando de elementos culturales vigentes en su comunidad a través de la recreación. (Herrera, L; 2016)

Actualmente la elaboración de productos a base del barro está siendo promovido y difundido por una cooperativa de mujeres ubicada en Las Cureñas. La artesana Luz Marina Herrera, se encuentra afiliada con otras doce mujeres en la Cooperativa San Expedito desde el año 2001, y a partir de esta organización han conservado la técnica de elaboración de productos de barro, siendo principalmente elaborados ollas, comales y adornos. 
La cooperativa ha permitido el rescate de este saber tradicional, y una vez organizadas iniciaron un proceso de capacitación e integraron el torno en la fabricación de la cerámica, y aunque se han incorporado diseños nuevos en la gama de artículos que se ofrecen al público, han procurado mantener los diseños originales que fueron aprendiendo de sus padres y abuelos.: donde aprendimos a hacer llaveros, pulseras, móviles, portavelas, y otros diseños. Pero siempre hacemos ollas y comales. Todo el proceso es natural (Herrera, L; 2016).

Se puede distinguir dos tipos de elaboración de cerámica de barro, una de manera rústica de color natural, y otra con más acabado y de más tiempo de cocción, que da como resultado una cerámica negra que resulta muy atractiva entre la población local, nacional e internacional.

Además del barro, también se utilizaba la fruta del jícaro y la madera para la elaboración de enseres del hogar, (panas, platos, cucharas), antes no había trastes de china, se usaba el barro para hacer los vasos, platos, ollas. También había otra fruta que le decían el calabazo, jícaro, del que se hacían unos guacalitos para tomar sopa, todo eso se usó y era indígena, estaban al alcance de nosotros (Herrera, L; 2016) sin embargo, su uso ha decaído completamente entre los habitantes de la comunidad, siguiendo vivo únicamente el trabajo artístico del barro. (Altamirano; 2016)
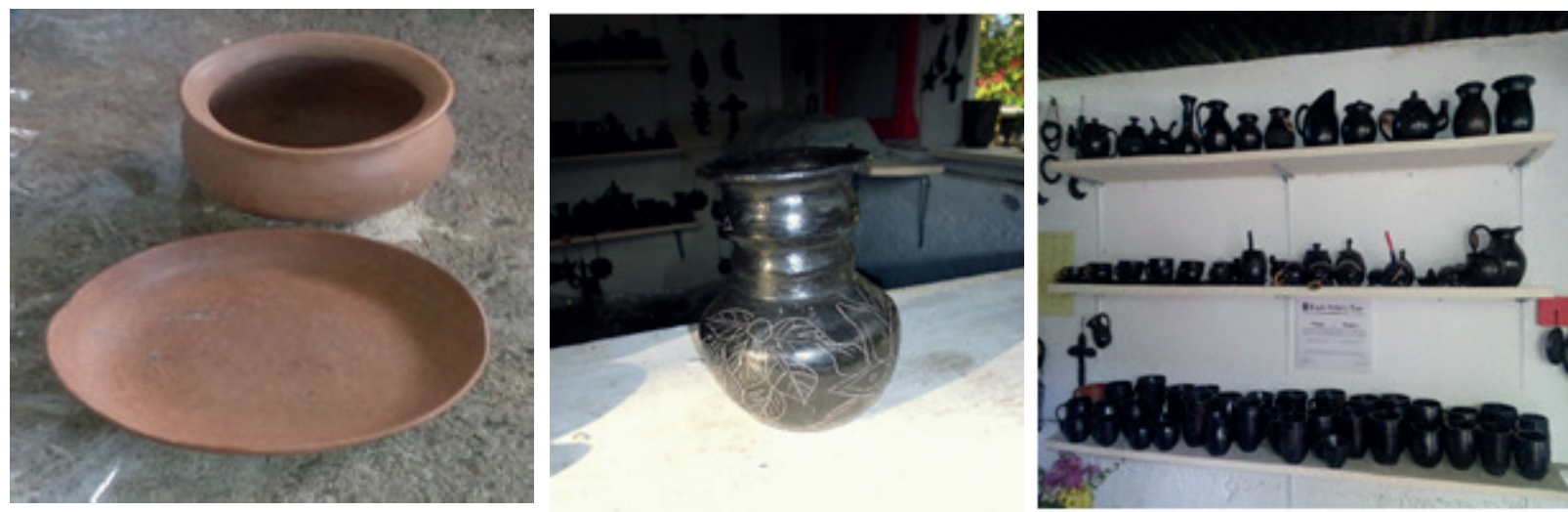

Diferentes tipos de cerámicas que se elaboran en la Cooperativa San Expedito Fuente: Fotografías tomadas a partir del trabajo de campo realizado en octubre de 2015

\section{Medicina natural}

Los saberes tradicionales también se evidencian en el uso de la medicina natural para contrarrestar enfermedades y males de la población. Es común encontrar en los patios de las casas pequeños huertos que contengan plantas como naranja agria, albahaca, sácate de limón, entre otros. Esta práctica ha sido heredada de generación en generación y su uso se fortalece con el paso del tiempo.

Enfermedades como fiebre, diarrea y dolores podían ser tratadas a partir del suministro de plantas, diferenciándose cada una de acuerdo a los males que presenta el individuo. Para ello, es importante que se pida el consentimiento de su uso a la planta en el afán de garantizar mayor efectividad: 
Hay diferentes enfermedades que nosotros sabemos la cura sin necesidad de antibióticas y medicina convencional. Es importantisimo pedir permiso. Si a mi me llega una paciente con dolor de corazón hay plantas exclusivas para el corazón, entonces voy donde la planta, le miento el nombre de la planta, me da permiso de tantas hojas porque las quiero para la julana de tal que tiene un problema tal, porque las plantas son vivas, igual que nosotros. Yo cuando me levanto abrazo las plantas, las saludo, eso es identidad, eso es amar a la naturaleza, Dios hizo todo perfecto, y hay una relación, vos sin las plantas no vivis (González, J; 2016).

Las plantas no son concebidas como una decoración más del hogar, sino que su presencia es determinada como un ser vivo que tiene consciencia completa de su entorno, y capaz de interferir a partir de su buen ánimo en el positivo efecto en el proceso de sanación. Por el contrario, si es agredida sin consultársele, esta podría resentirse y dejar de vivir, perdiéndose con ella todo su beneficio curativo.

Otro elemento que tienen en consideración cuando se utilizan las plantas con fines medicinales es la postura del sol, pues esta posición puede aliviar o intensificar los males de la persona que se encuentra enferma: Si la corta del lado donde se entierra el sol acorta la diarrea, pero si la corta del lado donde sale el sol puede empeorar... con otras enfermedades también... es muy raro que vayamos donde el médico... (Osegueda, E; 2016).

Las plantas cumplen una función favorable si se respeta el equilibrio completo de la naturaleza y todos los elementos que en ella se encuentran conviviendo, es decir, no solamente se trata de propiedades curativas que ya están por defecto en la planta sino la implementación de conocimiento milenario para hacer efectivo su uso racional y consentido.

En la actualidad, sigue viva la concepción curativa de las plantas, pues es evidente que son pocos los pobladores que se muestran incrédulos ante sus poderes medicinales, quienes prefieren asistir donde un "curandero" o conocedor de plantas para que les recete un "remedio" para sus males, antes de acudir al puesto médico. Esta idea se fortalece aún más con la realidad de que son pocas las comunidades que tienen presencia de centros o puestos de salud, tal vez se explique en que esto no representa una demanda permanente de la comunidad, quienes se sienten complacidos con la aplicación de medicina natural.

\section{Parteras y curanderos}

En este mismo sentido, las parteras y curanderos son los principales guías espirituales que conservan y aprovechan los conocimientos que de uso de los recursos naturales: tenemos las parteras, los curanderos, los médicos naturistas nuestros, que curan enfermedades que la ciencia médica no le haya... un abanico de conocimiento que nuestros abuelos nos han inculcado (González, J; 2016).

Las parteras, en el pasado eran concebidas como personas sabias que mantenían una conexión especial con la naturaleza, y que servían positivamente a los habitantes. Se sigue manteniendo la idea consagrada de estas guías, pero su uso se está disminuyendo a causa de la fuerte promoción que existe del uso de los puestos de salud convencionales para los partos.

En principio, atendían a las mujeres en las labores de parto, curaban a los bebés de enfermedades 
comunes como empachos, males de ojo, caída de mollera. Otra tarea de las parteras era aconsejar a las mujeres durante el período de gestación, y advertían sobre los cuidados que debían tener para garantizar un parto seguro. Migdalia López, partera de generaciones comentaba al respecto:

Cuando una mujer está embarazada se le recomienda tener reposo, no andar levantando peso, alimentarse bien...cuando tiene sintomas de aborto la acuesto, ligo su cadera y le preparo un cocimiento que lleva principalmente canela, granos de cacao, hojas de limón, pimienta, hojas de naranja agria, una cerveza, miel de jicote... Se soba la barriga a la parturienta, se tantea, si hecha liquidos es tiempo del parto, se prepara un cocimiento con manzanilla, apazote, hojas de naranja agria, hojas de limón, esencia de espiritu de castor, agua florida, espamofin y novalgina (Romero; 2009: 29).

Una vez que las mujeres entraban en trabajo de parto encomendaban a la mamá y al bebé a San Ramón, patrón de las parturientas, para que posibilitara un proceso seguro y rápido. En esta línea Teresa de Jesús Aranís, partera tradicional señala: Cuando una mujer está con dolores, se le prepara un cocimiento a base de canela, hojas de limón y manzanilla, si se le quita no es tiempo de parto, sino se sigue dando con cáscara de coralito tres veces nada más, en todo este proceso debe haber bastante sábanas y ropa limpia para cubrir a la madre y al bebé, sino a la madre le puede dar un espasmo y el bebé resfriarse (Romero; 2009: 32).

Al nacer el bebé se cortaba el ombligo a tres centímetros de la raíz, y con un clavo caliente desinfectado se le quemaba para suturar y evitar una posible hemorragia. De igual manera, se le hacía un parchecito con camíbar, liquidámbar, sulfatiazol, alcanfor y cebo para cicatrizar, por último, se aseguraba todo esto con gasas y un fajero: antes quemaban con alcanfor, sino le ligaban el ombligo y después con un clavo quemado... y quedaban sanitos (González, D; 2016).

En este momento, si el bebé salía muy sucio se bañaba con agua de manzanilla y hojas de naranja agría, de lo contrario, solamente se limpiaba, lo envolvía en una sábana y se ponía a dormir.

El uso de las sábanas blancas era un requisito fundamental durante y después del parto, también a la madre se le vestía de este mismo color, en primera instancia por salubridad, y en seguida, porque así la partera podía detectar rápidamente si se presentaban sangrados en la mujer e irregularidades, las manchas rojas de sangre eran más evidentes en ropa y sábanas blancas.

La partera abandonaba la casa de la parturienta después de tres días, durante este tiempo, se ocupaba de la mamá, el recién nacido y los otros hijos, preparando los alimentos de ellos y del cuido de la casa. Una vez que estaba segura la madre y el recién nacido, abandonaba la casa y regresaba a los ocho días para verificar que este botara su ombligo y enterrarlo en el patio de la casa, pues se tenía la creencia de que este acto garantizaba que el recién nacido desarrollara amor por su tierra:

A veces se quedaba dias atendiendo a los otros niños y al tierno, decía ya está seguro, ya está tranquilo, ya defecó, ya orinó y va de viaje. A los ocho dias llegaba para ver si el niño ya habia botado el ombligo, sino le ponia el injundio de gallina con alcanfor, yodo o alcohol crudo, pero sin quemarle la piel al niño (González, D; 2016). 
Posteriormente, la partera realizaba visitas esporádicas para vigilar el crecimiento del bebé, y se desligaba completamente hasta los cuarenta días de nacido sino se presentaba ninguna complicación. Era un trabajo de consagración y solemnidad, que se reconocía inclusive en la adultez de los niños, a quien se le instruía que guardaran respeto, admiración y agradecimiento a la mujer que los había traído al mundo, quien habría abandonado su casa y propios hijos para apoyar a las mujeres en un proceso tan agotador como era el parto.

A pesar de su loable labor, las parteras no recibían remuneración económica por sus servicios, sin embargo, le obsequiaban animales o granos como muestras de agradecimiento por la tarea desarrollada, Daysi González, aprendió el oficio de partera de su abuela, a quien le confiaban esta responsabilidad con previa anticipación: La contrato para tal fecha le decían ...Antes la gente era así, le estoy engordando un chancito, entonces ya sabía que estaba comprometida y que ese mes no salía para ningún lado (González, D; 2016).

Las parteras ocultaban su trabajo a los niños, inclusive a los de su propia familia, cuando se ausentaban por días decían que iban a sacar un cusuquito para despistarlos.

En la actualidad, las parteras sirven de guías para las mujeres durante el embarazo, sin embargo, ya no ejercen su papel de partera propiamente dicho, pues el Ministerio de Salud las ha potenciado únicamente como facilitadoras de los centros de salud, es decir, son las encargadas de remitir a las embarazadas hacia los centros, clínicas u hospitales cuando entran en labor de parto. Ya no deben atender los partos en el hogar, al menos que este sea inminente.

Debe de rescatarse como un elemento positivo la disposición de mantener a las parteras como piezas claves en la atención de embarazadas y a pesar de que el gobierno central ha establecido centros o puestos de salud en el casco urbano principalmente, no se ha desplazado completamente a esta de las tareas que tradicionalmente han ejercido como consejeras y sobadoras.

\section{Mitos, leyendas y creencias}

Entre las creencias que forman parte de la identidad étnica de las comunidades indígenas se encuentra la aceptación de la existencia de un ser supremo, quien hace posible la vida y todo lo que existe en la tierra, y a quien deben reverencia. Los animales son un ejemplo para nosotros, los pájaros le dan gracias a Dios todos los días, dan gracias cuando sale el sol, si una vaca se va a echar primero se inca para echarse, rinden culto al ser que los creó. (González, J; 2016).

Existe un fuerte apego a la naturaleza, que se evidencia en la creencia de considerar que los elementos (tierra, aire, agua.) tienen la capacidad de

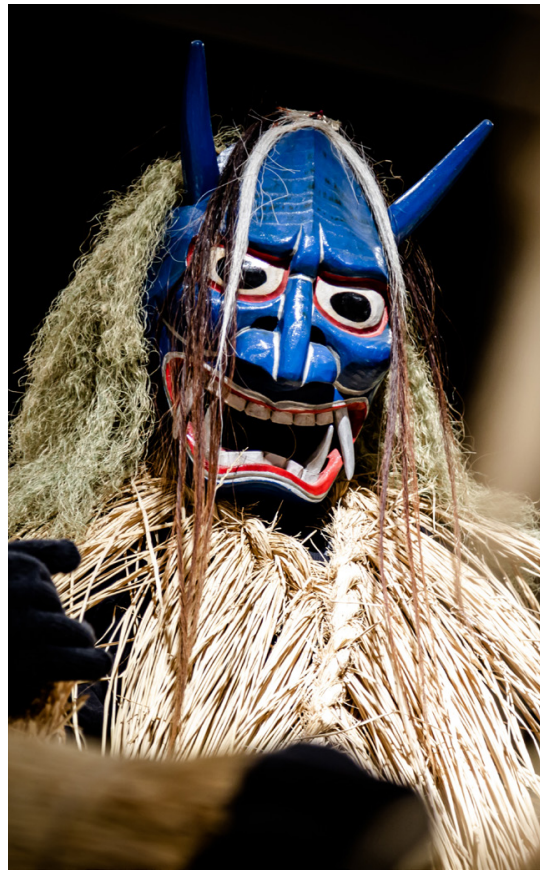


conceder salud y bienestar para aquellos que tienen fe: Si usted va a una quebradita y lleva una enfermedad, usted le reza al espíritu del agua, se toma un vaso de agua de esa y usted se cura, porque el agua tiene vida y limpia el organismo, siempre y cuando todo se haga con respeto... Todos tenemos vida en el planeta (González, J; 2016).

En este mismo sentido, el sol se presenta como fuente de energía, por lo tanto, se debe hacer reverencias al astro con el afán de obtener sus favores: Según nuestra cultura el sol es el que da energía, y alimenta a las plantas. Nosotros teníamos un culto especial al sol, nuestros abuelos, guías espirituales decían que hay un solo creador, así como son creadas por ese ser superior tienen una función especial, por ejemplo, si no hubiera la luna no hubiera marea, sino hubiera luna nueva no sembráramos. (González, J; 2016).

Los cuatros puntos cardinales proyectan un significado particular, más allá de la apropiación de la ubicación espacial, estos establecen elementos fundamentales en su vida diaria:

Se rendia culto a los cuatros puntos cardinales. Cada familia se rendia culto a la salida del sol que es de donde viene la energía positiva, después uno se ponía de pie al norte donde está la sabiduria, la inteligencia, y se hacía una ceremonia en la puesta del sol, los lugares oscuros dicen ellos, que es el lugar donde descansan todos los espiritus de nuestros abuelos, y al sur porque alli es el origen de nuestra raiz ancestral, porque vinieron del sur, yo siempre lo hago en la mañana al amanecer. Cuando uno va a ser esas reverencias o invocaciones siempre tiene que hacerlo descalzo porque la tierra es un ser vivo $y$ decian nuestros abuelos que a la tierra no hay que golpearla, ni golpear el agua... en mi casa tengo un circulo sagrado, el toten, circulo becho de plantas ornamentales, siempre con una entrada que se le deja a la salida del sol (este) porque esa es la entrada sagrada" (González, J; 2016).

Una de las creencias que prevalece en la comunidad es el aviso anticipado de futuras visitas a partir del canto de un pájaro (güis) y el zumbido fuerte del que se produce en el fuego, en ambos casos se anunciaba que la familia va a recibir visita, para ello, los anfitriones preparan comida y café para recibir a los viajantes.

De igual manera sigue presente la creencia de que los niños recién nacidos no pueden ser visitados por personas agitadas o mujeres con menstruación, también no se saca descubierto al sereno para evitar salpullido. Para evitar que el sereno lo perjudique se inmuniza con la luna. Durante la luna llena se saca al aire libre desnudo al bebé, se pone frente a ella, luego de espalda, y luego lo envuelven bien. De igual manera, se pone su ropita a serenar, seguidamente se le pone y el sereno ya no le afectará. (Romero; 2009: 34).

También se mantiene la creencia de enterrar el ombligo de los recién nacidos en los patios de sus hogares para garantizar que en el futuro el infante ame a su comunidad y a la patria. (Romero; 2009; 31). 
En el seno de las comunidades de estudio se comparten mitos y leyendas propias de la idiosincrasia nicaragüense, tales como La cegua, una mujer muy alta con la cara desfigurada y cabello largo hasta los talones, dientes de caballo y que si la mira fijamente le pierde en el camino. (Altamirano; 2016).

El cadejo también es un actor que hace presencia en las comunidades. Se diferencian dos tipos, uno negro que es asociado al varón y uno blanco que es compañía de la mujer: yo lo he visto, es amigo de uno, ese espíritu se pega detrás de mí, me acompaña en mi camino por las noches y madrugadas. Son cosas que uno tiene que ir conviviendo con ella, cosas que no son malas, sino que son para proteger a la persona y a todo lo que está creado, todo tiene un significado, un valor. (González, J. 2016).

De igual manera se habla de duendes, criaturas semejantes a hombres pequeños que andan en busca de niños para llevárselos hacia el corazón de las montañas: Duendes, son chiquitos y barbones, hay dos clase, el rojo y el verde, y solo son risa. El rojo es menos agresivo, si el verde toca una niña se la lleva (Altamirano; 2016).

Entre los mitos propios de la población local, se registra El Guardián de la fauna de Yuca Puca, un chavalito pequeño que aparece y espanta a las personas que se internan en la montaña con las intenciones de cazar a los animales: allí hay cusucos, conejos y animales de monte, un niño normal como de dos años vestido con un chorcito pierde -al cazador- o le corre a los perros. (González, J. 2016)

El Príncipe del Gobiado, se dice que tiene una cueva en el cerro de nombre Gobiado y que busca un niño sin bautismo para él desencantarse y que el niño sea el nuevo príncipe. Gente muy formal asegura haberlo encontrado en los caminos de noche y de día, montado en un gran caballo negro, la camisa es bordada y ofrece una gran cantidad de dinero a los padres del niño. (Romero; 2009; 19)

En el centro de Santa María de Pantasma, se estableció una tribu indígena y por razones desconocidas abandonaron la zona dejando un sembrillo para que nadie ocupara las tierras, habían sembrado muchos árboles frutales, cítricos y el intruso que llegaba a la zona y comía frutos enfermaba de fiebre y moría, solo 8 días podía estar en el lugar. (Romero; 2009, 34)

La leyenda del Grito, es sobre un hombre que hizo pacto con el diablo, con el paso de los años él buscaba como liberarse de esa maldición, para ello, siempre andaba en busca un niño sin bautismo que entregaría a cambio de su alma. Se decía que se le miraba rondando los caminos cercanos al lago, donde se escucha un grito y el relincho del caballo. (Romero; 2008: 25)

Estas son algunas de las tradiciones orales que se mantienen vigentes en la comunidad, y que forman parte de su diario vivir, algunas quedan en la memoria como mitos, pero que ninguno se atreve a comprobar, pues en el fondo, hay un sentimiento de creencia que les invita a creer y reconocer esa cosmovisión. 


\section{Conclusiones}

La cultura e historia de los pobladores de la comunidad indígena de Jinotega, se ha diseñado a partir del elemento tierra que condiciona otras expresiones de identidad como el uso tradicional de la medicina natural y la elaboración de cerámica de barro. De igual manera, se encuentra arraigada las creencias comunitarias, entrelazadas entre el mito y la leyenda, donde sobresalen lazos de solidaridad y actividades de buena vecindad.

Existe viva en la memoria de la comunidad, el uso de sus médicos tradicionales conocidos popularmente como curanderos, quienes son encargados de suministrar las dosis exactas de las hierbas, prolongando así su continuidad y fortalecimiento con el paso de los años. Su trabajo está asociado fuertemente a la conexión que mantienen con la naturaleza, quien les proporciona el conocimiento y sabiduría para suministrar y aprovechar los beneficios sin perjuicio del hombre, ni del medio que les rodea.

Los saberes y creencias pesan mucho en el imaginario de la población étnica, pues consideran que son experiencias acumuladas que han sido heredadas de sus antepasados, a partir de la oralidad y por lo tanto, sirven de lección y guía para las generaciones presentes y futuras. Esto obedece a que existe un fuerte apego y respeto por las personas de mayor edad, a quienes se les considera con experiencia y sabiduría, elemento que dista mucho de la cultura occidental, donde se le suele menospreciar y excluir. Aquí los ancianos ocupan puestos importantes dentro de la comunidad como concejeros, mediadores y líderes naturales.

En el espacio de estudio se comparten muchos mitos y leyendas que forman parte de la idiosincrasia nicaragüense, pero de igual forma, se desarrollan otros propios de la comunidad, los que son recreados en el paisaje y condiciones propias de la zona, contribuyendo de esta manera a crear una base cultural propia que los identifica como grupo poblacional, contribuyendo significativamente en la creación de vínculos particulares entre los miembros de la misma localidad, que se traduce en la formación de una identidad étnica.

\section{Referencias bibliográficas}

- Guerrero J, y Soriano, L. (1967) Monografía de Matagalpa. Managua, Nicaragua.

- Membreño, M. (1998) La estructura de las comunidades étnicas. Itinerario de una investigación teórica desde Nicaragua. Editorial Envío. Abril, Managua, Nicaragua.

- Pérez, F. (1956) Las Comunidades indígenas en Nicaragua. Universidad de San Carlos: Guatemala.

- Romero, J. (Coordinadora) (2005) Región Norte Central de Nicaragua, Matagalpa y Jinotega a través de su historia. UNAN: Nicaragua.

- Romero, J. (Coordinadora) (2009) Nuestras Comunidades: Una mirada histórica a los pueblos indígenas del Pácifico, Centro y Norte de Nicaragua. UNAN: Nicaragua. 
- Romero, J. (Coordinadora). (2008) Memoria e Historia de un Proyecto Social. Trabajar el presente para construir el futuro, UNAN-Managua, Nicaragua

- Romero, J. (Coordinadora). Abriendo Surcos. Memoria de actividades de capacitación llevadas a cabo en el municipio de Jinotega, mayo-agosto 2005. UNAN-Managua, Nicaragua.

- Romero, J. (Coordinadora). La madre tierra a flor de piel. Memoria e Historia de un Proyecto Social. Diciembre, 2007, UNAN-Managua, Nicaragua.

- Romero, J. (Coordinadora). Memoria e Historia de un Proyecto Social. El trabajo en el pueblo indígena de Jinotega. Diciembre, 2006, UNAN-Managua, Nicaragua

- Romero, J. (Coordinadora). Ya estamos construyendo el futuro. Memoria e Historia de un proyecto social. Managua, UNAN, 2009.

- Wheelock, Jaime. (1981) Raíces indígenas de la lucha anticolonialista en Nicaragua). Editorial Nueva Nicaragua: Nicaragua.

\section{Fuentes orales}

- Luis González Torres (González, L). Entrevista individual realizada por Marvin Villalta en ciudad Jinotega el 16 de mayo de 2016.

- Luz Marina Herrera (Herrera, L) Entrevista individual realizada por Ruth González García en comunidad indígena de Las Cureñas, Jinotega, el 27 de octubre de 2016.

- José Luis González (González, J) Entrevista colectiva realizada por Ruth González García en ciudad Jinotega el 28 de octubre de 2016.

- Herman Osegueda Altamirano (Osegueda, H) Entrevista colectiva realizada por Ruth González en Ciudad Jinotega, el 28 de octubre de 2016. 